\title{
Optimal usage of the GnRH antagonists: a review of the literature
}

\author{
Alan B Copperman ${ }^{1,2^{*}}$ and Claudio Benadiva ${ }^{3}$
}

\begin{abstract}
Gonadotropin-releasing hormone (GnRH) antagonists, which became commercially available from 1999, have been used for the prevention of premature luteinizing hormone $(\mathrm{LH})$ surges in controlled ovarian stimulation for in vitro fertilization or intracytoplasmic sperm injection. This review focuses on the recent literature on the use of GnRH antagonists and provides guidelines for optimal use in light of increasing evidence showing that $\mathrm{GnRH}$ antagonists are safe and effective, allowing flexibility of treatment in a wide range of patient populations. This includes patients undergoing first-line controlled ovarian stimulation, poor responders, and women diagnosed with polycystic ovary syndrome. The $\mathrm{GnRH}$ antagonist offers a viable alternative to the long agonists, providing a shorter duration of treatment with fewer injections and with no adverse effects on assisted reproductive technology outcome. This results in a significantly lower amount of gonadotropins required, which is likely to lead to improved patient compliance.
\end{abstract}

Keywords: GnRH antagonists, GnRH agonists, IVF, Ovarian stimulation, OHSS

\section{Background}

Gonadotropins were first introduced in the early 1960s and have been used in ovarian stimulation cycles to induce multiple follicular development, particularly during the past 3 decades, in women undergoing in vitro fertilization (IVF) treatment. Gonadotropin-releasing hormone (GnRH) analogs are administered along with gonadotropins to prevent the occurrence of a surge in luteinizing hormone (LH), which may occur prematurely before the leading follicle reaches the optimum diameter $(\geq 17 \mathrm{~mm})$ for triggering ovulation by human chorionic gonadotropin (hCG) injection. Without the use of GnRH analogs, LH surges would occur in approximately $20 \%$ of stimulated IVF patients [1,2]. Preventing LH surges using GnRH analogs improves oocyte yield with more embryos, allowing better selection and, therefore, leading to an increase in pregnancy rates [3].

Since the early 1980s, the use of GnRH agonists in ovarian stimulation has greatly improved the success rate of IVF [4]. GnRH agonists reduce the incidence of premature LH surges $[5,6]$ by suppressing gonadotropin

\footnotetext{
* Correspondence: acopperman@rmaofny.com

${ }^{1}$ Mount Sinai Medical Center, New York, NY, USA

${ }^{2}$ Reproductive Medicine Associates of New York, New York, NY, USA Full list of author information is available at the end of the article
}

release via pituitary desensitization following an initial short period of gonadotropin hypersecretion. More recently, GnRH antagonists with high potency and fewer side effects have been introduced into IVF and have emerged as an alternative in preventing premature $\mathrm{LH}$ surges. Unlike GnRH agonists, these potent GnRH antagonists cause immediate, rapid gonadotropin suppression by competitively blocking GnRH receptors in the anterior pituitary gland, thereby preventing endogenous GnRH from inducing $\mathrm{LH}$ and follicle-stimulating hormone (FSH) release from the pituitary cells. Furthermore, GnRH antagonist suppression of gonadotropin secretion can be quickly reversed [7-9]. This different pharmacologic mechanism of action makes GnRH antagonists a more logical choice to use in IVF for the prevention of premature LH surges [5].

Ganirelix (Orgalutran, N.V. Organon, Oss, The Netherlands) and cetrorelix (Cetrotide, Serono International S.A., Geneva, Switzerland) are subcutaneously administered GnRH antagonists approved for clinical use in IVF therapy [10,11]. Since 1999, GnRH antagonists have been used for the prevention of premature LH surges in women undergoing controlled ovarian stimulation for IVF. Clinically, stimulation with urinary FSH or recombinant human FSH $(\mathrm{rFSH})$, either alone or in combination

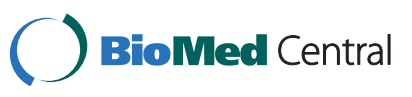


with urinary-derived human menopausal gonadotropin (hMG), is started on day 2 or 3 of the menstrual cycle and the GnRH antagonist is administered in the late follicular phase, from day 5 or 6 of stimulation onward. The dose of gonadotropins may be adjusted according to individual response. Both gonadotropins are continued daily until two to three follicles reach $\geq 17 \mathrm{~mm}$ in diameter (on ultrasound assessment) at which time hCG is administered to induce final oocyte maturation (Figure 1). This review focuses on literature concerning the use of $\mathrm{GnRH}$ antagonists in ovarian stimulation for IVF and provides guidelines for optimal use.

\section{Potential advantages of GnRH antagonist protocols}

There are a number of theoretical advantages of $\mathrm{GnRH}$ antagonists versus $\mathrm{GnRH}$ agonists [12,13], including a shorter duration of injectable drug treatment, absence of vasomotor symptoms, less risk of inadvertent administration during early pregnancy, avoidance of ovarian cyst formation, and a significantly smaller dose of gonadotropin per cycle, which translate to improved patient convenience $[9,14]$. The literature regarding the cost effectiveness of $\mathrm{GnRH}$ antagonist protocols is currently contradictory. In a randomized trial by Badrawi et al. [15], the cost of medication per cycle and per pregnancy was shown to be higher in a $\mathrm{GnRH}$ antagonist protocol than a $\mathrm{GnRH}$ agonist protocol, while an observational study by Kamath et al. [16] found costs of the two protocols to be similar.

Current evidence suggests that GnRH antagonists and agonists are similarly effective in the context of oocyte donation [17]. However, due to their increased convenience, $\mathrm{GnRH}$ antagonist protocols are often the regimen of choice for oocyte donors. More recently, it has been recommended that treatment guidelines for the prevention of ovarian hyperstimulation syndrome (OHSS) [18] should be updated to incorporate findings from the literature over the past 5 years. The literature shows that $\mathrm{GnRH}$ antagonist protocols and $\mathrm{GnRH}$ agonist triggering of final oocyte maturation, especially when used in combination, may reduce OHSS and have considerable promise in preventing OHSS [19].

\section{Potential disadvantages of GnRH antagonist protocols}

Potential disadvantages of $\mathrm{GnRH}$ antagonist protocols over $\mathrm{GnRH}$ agonist protocols include less flexible options in terms of cycle programming and early studies suggesting a minor reduction in pregnancy rates per cycle $[20,21]$. Increasing flexibility of $\mathrm{GnRH}$ antagonist protocols can be achieved with oral contraceptives [20]. Pretreatment with oral contraceptives allows programming of cycles, whereby stimulation can be started during a 5-day interval following withdrawal of the oral contraceptive [22]. Use of oral contraceptives with a GnRH antagonist protocol and the pregnancy outcomes of GnRH antagonist protocols are discussed below.

\section{Pregnancy outcomes of GnRH antagonist protocols}

Despite an initial trend toward a lower pregnancy rate with GnRH antagonists compared with agonists in a number of early randomized controlled studies, a metaanalysis by Kolibianakis et al. [23] and a review by TurKaspa and Ezcurra [24] found no significant difference in the probability of live birth rates with the use of either a GnRH agonist or antagonist protocol [23] (Table 1).

In normal responders, the use of $\mathrm{GnRH}$ antagonist versus long GnRH agonist protocols was associated with a statistically significant reduction of OHSS, with no evidence of a difference in live birth rates [45]. GnRH antagonist protocols have been shown to result in better outcomes than GnRH agonists in patients with poor prognosis [52,53]. In a meta-analysis of six clinical trials comparing $\mathrm{GnRH}$ antagonist versus $\mathrm{GnRH}$ agonist protocols in poor ovarian responders in IVF/intracytoplasmic sperm injection (ICSI) cycles Franco et al. [54] indicated no difference between $\mathrm{GnRH}$ antagonists and agonists with respect to cycle cancellation rate, number of mature oocytes, and clinical pregnancy rate per cycle initiated, per oocyte retrieval, and per embryo transfer. Al-Inany et al.

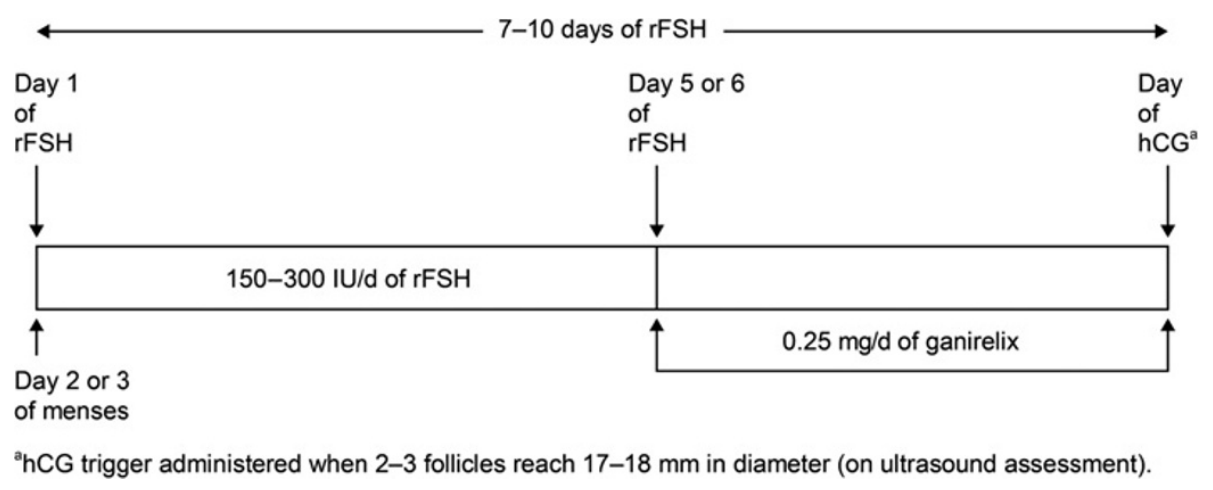

Figure 1 Schematic presentation of the ganirelix treatment regimen. 
Table 1 Results of meta-analyses of GnRH analogs among patients treated for IVF - odds ratio of live birth rate

\begin{tabular}{|c|c|c|c|c|c|c|}
\hline & GnRH antagonists & & GnRH agonists & & Weight & Odds ratio $(95 \% \mathrm{Cl})$ \\
\hline & Events & Total & Events & Total & & \\
\hline \multicolumn{7}{|c|}{ RCTs included in Kolibianakis et al. [23] } \\
\hline Albano 2001 [25] & 34 & 198 & 19 & 95 & & $0.83(0.44-1.55)$ \\
\hline European 2000 [8] & 97 & 486 & 61 & 244 & & $0.75(0.52-1.08)$ \\
\hline Olivennes 2000 [26] & 22 & 126 & 9 & 43 & & $0.80(0.34-1.90)$ \\
\hline N American 2001 [27] & 60 & 208 & 36 & 105 & & $0.78(0.47-1.28)$ \\
\hline Middle East 2001 [28] & 72 & 236 & 37 & 119 & & $0.97(0.60-1.57)$ \\
\hline Akman 2001 [29] & 4 & 24 & 5 & 24 & & $0.76(0.18-3.26)$ \\
\hline Hohmann 2003 [30] & 18 & 111 & 10 & 58 & & $0.93(0.40-2.17)$ \\
\hline Martinez 2003 [31] & 4 & 21 & 3 & 23 & & $1.57(0.31-8.01)$ \\
\hline Franco 2003 [32] & 3 & 14 & 2 & 6 & & $0.55(0.07-4.56)$ \\
\hline Hwang 2004 [33] & 8 & 27 & 8 & 29 & & $1.11(0.35-3.53)$ \\
\hline Sauer 2004 [34] & 9 & 24 & 9 & 25 & & $1.07(0.33-3.41)$ \\
\hline Loutradis 2004 [35] & 9 & 58 & 12 & 58 & & $0.70(0.27-1.63)$ \\
\hline Check 2004 [36] & 8 & 30 & 5 & 30 & & $1.82(0.52-6.38)$ \\
\hline Xavier 2005 [37] & 7 & 66 & 8 & 65 & & $0.85(0.29-2.48)$ \\
\hline Malmusi 2005 [38] & 5 & 30 & 5 & 30 & & $1.00(0.28-3.89)$ \\
\hline Marci 2005 [39] & 4 & 30 & 0 & 30 & & $10.38(0.53-201.45)$ \\
\hline Cheung 2005 [40] & 3 & 33 & 2 & 33 & & $1.55(0.24-9.94)$ \\
\hline Barmat 2005 [41] & 13 & 40 & 17 & 40 & & $0.65(0.26-1.62)$ \\
\hline Bahceci 2005 [42] & 29 & 73 & 33 & 75 & & $0.84(0.44-1.61)$ \\
\hline Badrawi 2005 [15] & 11 & 50 & 13 & 50 & & $0.80(0.32-2.02)$ \\
\hline Schmidt 2005 [43] & 3 & 24 & 3 & 24 & & $1.00(0.18-5.53)$ \\
\hline Lee 2005 [44] & 13 & 41 & 8 & 20 & & $0.70(0.23-2.11)$ \\
\hline Total $(n=22)$ & 436 & 1950 & 305 & 1226 & & $0.86(0.72-1.02)$ \\
\hline \multicolumn{7}{|c|}{ RCTs included in Al-Inany et al. [45] } \\
\hline \multicolumn{7}{|l|}{ All women } \\
\hline Albano 2000 [25] & 34 & 198 & 19 & 95 & $13.5 \%$ & $0.83(0.44-1.55)$ \\
\hline Barmat 2005 [41] & 13 & 40 & 17 & 40 & $7.3 \%$ & $0.65(0.26-1.62)$ \\
\hline Heijnen 2007 [46] & 70 & 205 & 78 & 199 & $33.0 \%$ & $0.80(0.54-1.21)$ \\
\hline Hurine 2006 [47] & 17 & 91 & 17 & 91 & $8.8 \%$ & $1.00(0.47-2.11)$ \\
\hline Kim 2009 [48] & 13 & 54 & 8 & 28 & $5.1 \%$ & $0.79(0.28-2.22)$ \\
\hline Kurzawa 2008 [49] & 14 & 37 & 18 & 37 & $7.1 \%$ & $0.64(0.25-1.62)$ \\
\hline Lin 2006 [50] & 22 & 60 & 21 & 60 & $8.4 \%$ & $1.08(0.51-2.27)$ \\
\hline Marci 2005 [39] & 4 & 30 & 0 & 30 & $0.3 \%$ & $10.36(0.53-201.45)$ \\
\hline Ye 2009 [51] & 35 & 109 & 39 & 111 & $16.6 \%$ & $0.87(0.50-1.53)$ \\
\hline Subtotal $(95 \% \mathrm{Cl})$ & & 824 & & 691 & $100.0 \%$ & $0.86(0.69-1.08)$ \\
\hline Total events & 222 & & 217 & & & \\
\hline Heijnen 2007 [46] & 70 & 205 & 78 & 199 & $79.7 \%$ & $0.80(0.54-1.21)$ \\
\hline Lin 2006 [50] & 22 & 60 & 21 & 60 & $8.4 \%$ & $1.08(0.51-2.27)$ \\
\hline Subtotal $(95 \% \mathrm{Cl})$ & & 265 & & 259 & $100.0 \%$ & $0.89(0.62-1.26)$ \\
\hline Total events & 97 & & 102 & & & \\
\hline
\end{tabular}

Heterogeneity: $X^{2}=0.32, d f=1(P=0.57)$

Test for overall effect: $Z=0.66(P=0.51)$ 
Table 1 Results of meta-analyses of GnRH analogs among patients treated for IVF - odds ratio of live birth rate (Continued)

\begin{tabular}{|c|c|c|c|c|c|c|}
\hline \multicolumn{7}{|l|}{ Cetrorelix only } \\
\hline Albano 2000 [25] & 34 & 198 & 19 & 95 & $26.3 \%$ & $0.83(0.44-1.55)$ \\
\hline Hurine 2006 [47] & 17 & 91 & 17 & 91 & $17.1 \%$ & $1.00(0.47-2.11)$ \\
\hline Kim 2009 [48] & 13 & 54 & 8 & 28 & $9.9 \%$ & $0.79(0.28-2.22)$ \\
\hline Kurzawa 2008 [49] & 14 & 37 & 18 & 37 & $13.8 \%$ & $0.64(0.25-1.62)$ \\
\hline Marci 2005 [39] & 4 & 30 & 0 & 30 & $0.5 \%$ & $10.36(0.53-201.45)$ \\
\hline Ye 2009 [51] & 35 & 109 & 39 & 111 & $32.4 \%$ & $0.87(0.50-1.53)$ \\
\hline Subtotal $(95 \% \mathrm{Cl})$ & & 519 & & 392 & $100.0 \%$ & $0.89(0.65-1.23)$ \\
\hline Total events & 97 & & 102 & & & \\
\hline \multicolumn{7}{|l|}{ Heterogeneity: $x^{2}=3.31, d f=5(P=0.65)$} \\
\hline \multicolumn{7}{|l|}{ Test for overall effect: $Z=0.70(P=0.49)$} \\
\hline \multicolumn{7}{|l|}{ Ganirelix only } \\
\hline Barmat 2005 [41] & 13 & 40 & 17 & 40 & $100.0 \%$ & $0.65(0.26-1.62)$ \\
\hline Subtotal $(95 \% \mathrm{CI})$ & & 40 & & 40 & $100.0 \%$ & $0.65(0.26-1.62)$ \\
\hline Total events & 97 & & 102 & & & \\
\hline \multicolumn{7}{|l|}{ Heterogeneity: not applicable } \\
\hline Test for overall effect: $Z=0.70(P=0.36)$ & & & & & & \\
\hline
\end{tabular}

[45] found no significant difference following the use of GnRH antagonist and agonist protocols in a recent Cochrane review.

In oocyte donation [55] and embryo transfer [56] cycles, the replacement of GnRH agonist with a GnRH antagonist had no impact on the pregnancy and implantation rates. Higher pregnancy rates were also shown in a gonadotropin intrauterine insemination cycle than in a cycle where no intervention took place [57]. In a prospective randomized trial, Prapas et al. [58] reported that GnRH antagonist administration during the proliferative phase did not adversely affect endometrial receptivity in oocyte recipients.

\section{Optimal use of $\mathrm{GnRH}$ antagonists in diverse treatment situations \\ First-line treatment}

GnRH antagonists have been shown to be an effective treatment in women undergoing controlled ovarian stimulation for IVF in multiple meta-analyses and clinical studies. In the systematic review and meta-analyses by Kolibianakis et al. [23], it was shown that the probability of live birth was not dependent on the type of GnRH ana$\log$ used for the suppression of premature LH rises (odds ratio 0.86 ; $95 \%$ confidence interval $0.72-1.02$ ). In a more recent systematic review, Al-Inany et al. [45] also reported that there was no significant difference in live birth rates following a $\mathrm{GnRH}$ antagonist or $\mathrm{GnRH}$ agonist protocol (odds ratio $0.86,95 \%$ confidence interval 0.69-1.08).
In a retrospective review of patients with good prognosis undergoing their first IVF cycle, Johnston-MacAnanny et al. [59] showed that clinical and ongoing pregnancy rates and implantation rates were similar in 755 good responder patients undergoing a GnRH agonist protocol and 378 good responder patients undergoing a GnRH antagonist protocol during their first cycle of IVF. Borm and Mannaerts [8] evaluated the efficacy and safety of ganirelix in 730 women undergoing ovarian stimulation with rFSH. The patients were randomized in a 2:1 ratio to either 0.25 mg ganirelix or buserelin (the trial was designed as a noninferiority study using a long protocol of intranasal buserelin and $\mathrm{rFSH}$ as a reference treatment). Ganirelix in comparison with buserelin resulted in a shorter duration of treatment ( 5 vs 26 days). Comparison of the number and size of follicles indicated that in the ganirelix group, the final number of follicles on the day of hCG administration, was smaller (10.7 vs 11.8) and produced less peak estradiol concentration (1190 vs $1700 \mathrm{pg} / \mathrm{ml}$ ) than the buserelin group. The ganirelix regimen resulted in the recovery of good-quality oocytes, as reflected by the high fertilization rate $(62.1 \%)$, and a similar number of goodquality embryos (3.3), as the reference group (3.5). The clinical outcome (defined as the ongoing pregnancy rate per attempt) was good (20.3\%), although pregnancy rates were found to be slightly higher in the reference group $(25.7 \%)$. Interestingly, the ongoing pregnancy rate per attempt for patients treated at study sites $(n=10)$ that had previous experience with the ganirelix regimen was 
similar, that is, $24.2 \%$ in the ganirelix group vs $23.6 \%$ in the buserelin group. This suggests that the slightly lower pregnancy rates observed in early trials may have been related to lack of experience with the use of antagonist protocols. With regard to safety, ganirelix was found to be safe and well tolerated with a two-fold lower (2.4\%) incidence of OHSS than was found in the buserelin (5.9\%) group. Overall, the study demonstrated that ganirelix provides a safe, short, and convenient treatment option for patients undergoing controlled ovarian hyperstimulation for IVF/ICSI and results in good clinical outcome.

\section{Second-line treatment (treatment of poor responders)}

GnRH antagonists have been used effectively in patients who have a poor prognosis or who have shown a diminished ovarian response to controlled ovarian stimulation. In the systematic review and meta-analyses by Kolibianakis et al. [23], it was shown that the probability of live birth in poor responders was not dependent on the type of $\mathrm{GnRH}$ analog used for the suppression of premature $\mathrm{LH}$ rises (odds ratio 1.34; 95\% confidence interval 0.70-2.59). In a more recent systematic review, Al-Inany et al. [45] also reported no significant differences in clinical pregnancy rates in poor responders following a $\mathrm{GnRH}$ antagonist and GnRH agonist protocol (odds ratio 0.71, 95\% confidence interval 0.49-1.02).

Schmidt et al. [43] showed that the use of GnRH antagonists was as effective as the conventional microdose protocol and that embryo quality, implantation rates, and ongoing pregnancy rates were comparable in a randomized prospective study comparing ganirelix with a microdose $\mathrm{GnRH}$ agonist in patients with poor ovarian response. The microdose flare protocol has been proven to increase both clinical and ongoing pregnancy rates in poor responders. The authors concluded that the ganirelix protocol may be preferable because it requires significantly fewer injections and a shorter treatment course, resulting in cost savings and improved convenience for the patient. An earlier review by Copperman [60] also noted that the use of a GnRH antagonist for the suppression of premature LH surges in poor responders is at least as good as the microdose flare and provides better cycle outcomes than the long luteal leuprolide acetate downregulation protocols.

The use of $\mathrm{GnRH}$ antagonists among patients with poor prognosis was also evaluated by Shapiro et al. [12] in a nonrandomized, noncontrolled, retrospective review of 204 patients (165 cycles in patients with a normal IVF prognosis and 60 cycles in those with a poor prognosis). Overall, the pregnancy rates per initiated cycle and per embryo transfer were $33.3 \%$ and $42.1 \%$, respectively, with a cycle cancellation rate of $21 \%$. The patients with poor prognosis had a pregnancy rate of $8.3 \%$ per attempt and $15 \%$ per transfer compared with $40 \%$ and $45 \%$, respectively, in patients with normal prognosis. While this retrospective analysis supports the use of $\mathrm{GnRH}$ antagonist protocols as an alternative to agonist protocols in normal responders, the use of $\mathrm{GnRH}$ antagonists in patients with poor IVF prognosis resulted in predictably poor outcomes.

In a recent meta-analysis comparing the efficacy of $\mathrm{GnRH}$ antagonists versus agonists in poor responders, $\mathrm{Pu}$ et al. [61] showed that GnRH antagonists resulted in a shorter duration of stimulation, but there was no difference in the number of oocytes retrieved, the cycle cancellation rate, or the clinical pregnancy rate.

The ability to offer patients who have suffered numerous failed cycle attempts a choice of effective alternatives may improve outcomes for these women. Currently, in many centers, the luteal phase estradiol patch/GnRH antagonist (LPG) protocol is the treatment of choice for women with a poor response to ovarian stimulation. This protocol involves administration of transdermal estradiol patches and a $\mathrm{GnRH}$ antagonist in the luteal phase of the preceding menstrual cycle, followed by high-dose follicular phase gonadotropin stimulation with adjunctive $\mathrm{GnRH}$ antagonist. Dragisic et al. [62] first described this novel protocol in 2005 and demonstrated that it improved ovarian responsiveness among poor responders, with more uniform follicular development, more oocytes retrieved, higher number of transferred embryos, and improved pregnancy rates. Weitzman et al. [63] retrospectively compared the outcomes of patients with a history of failed cycles who had undergone ovarian stimulation with either an LPG protocol $(n=45)$ or a microdose agonist protocol $(n=76)$ over a 1-year period [63]. All clinical outcomes, including ongoing pregnancy rates, were comparable between the two groups, suggesting that the use of an LPG protocol is at least as effective as a microdose agonist protocol. Similar findings were obtained by the same group of investigators in a subsequent prospective randomized controlled trial (RCT) [64].

\section{Dosing schedules \\ Single dose}

Cetrorelix acetate, a US Food and Drug Administrationapproved GnRH antagonist, has been shown to be effective and safe as a single-dose (3 mg) or multiple-dose regimen $(0.25 \mathrm{mg}$ daily) $[65,66]$. In a prospective randomized trial, Vlaisvljevic et al. [67] showed that $3 \mathrm{mg}$ cetrorelix had comparable efficacy to the GnRH agonist goserelin. However, multiple-dose protocols are now the standard and single-dose protocols are rarely used.

\section{Multiple dose}

Ganirelix is only available as a multiple-dose regimen. The multiple-dose protocol for ganirelix involves the administration of $0.25 \mathrm{mg}$ daily from day 6 or 7 of stimulation, or when the leading follicle is $14-15 \mathrm{~mm}$, until 
hCG administration [68]. The Ganirelix Dose-Finding Study [69] was the first multicenter, double-blind, randomized dose-finding study to establish the minimal effective dose of ganirelix to prevent premature LH surges in 333 women undergoing ovarian stimulation with $\mathrm{rFSH}$. Six different ganirelix doses $(0.0652,0.125,0.25,0.5,1.0$, and $2.0 \mathrm{mg} / 0.5 \mathrm{ml}$ ) were administered daily by subcutaneous injection. In this study, patients were treated with a fixed dose of $150 \mathrm{IU}$ rFSH for 5 days before starting ganirelix. The study revealed that $0.25 \mathrm{mg} / \mathrm{d}$ was the minimal effective dose with regard to preventing LH surges and resulted in a good clinical outcome with an ongoing pregnancy rate of $34 \%$ per attempt and $37 \%$ per transfer. Administration of $0.25 \mathrm{mg}$ daily ganirelix has been shown to be safe and effective in the prevention of premature LH surge in further studies $[8,27,28]$.

The North American Ganirelix Study Group administered this $\mathrm{GnRH}$ antagonist to 313 patients for whom controlled ovarian hyperstimulation and IVF/ICSI were indicated [27]. Patients received one controlled ovarian hyperstimulation cycle with ganirelix or a long protocol of leuprolide acetate in conjunction with rFSH [27]. From day 6 of rFSH treatment, ganirelix $(0.25 \mathrm{mg})$ was administered daily up to and including the day of hCG administration. The mean number of oocytes retrieved per attempt was 11.6 in the ganirelix group and 14.1 in the leuprolide group. Fertilization rates were $62.4 \%$ and $61.9 \%$ and implantation rates were $21.1 \%$ and $26.1 \%$ in the ganirelix and leuprolide groups, respectively. Clinical and ongoing pregnancy rates per attempt, respectively, were $35.4 \%$ and $30.8 \%$ in the ganirelix group and $38.4 \%$ and $36.4 \%$ in the leuprolide acetate group. Fewer moderate and severe injection-site reactions were reported with ganirelix $(11.9 \%$ and $0.6 \%)$ than with leuprolide (24.4\% and $1.1 \%)$.

The European and Middle East Orgalutran Study Group, compared the use of ganirelix $(0.25 \mathrm{mg}$ administered from day 6 of rFSH treatment up to and including the day of hCG administration) with the GnRH agonist triptorelin $(0.1 \mathrm{mg})$, as a reference treatment in a long protocol [28]. Overall, the results showed that ganirelix achieved similar clinical efficacy with a shorter duration of treatment compared with the GnRH agonist. The ganirelix regimen was 17 days shorter (9 vs 26 days) than the triptorelin regimen with a median reduction in the total dose of rFSH utilized of 450 IU (1350 vs 1800 IU). The fertilization rates and the number of goodquality embryos were similar in both treatment groups. The implantation rates of the two treatment arms were identical (22.9\%) with similar ongoing pregnancy rates (31.0\% for ganirelix vs $33.9 \%$ for triptorelin). Furthermore, local tolerance of ganirelix appeared to be better than that of triptorelin, as the percentage of subjects with at least one local skin reaction was two-fold lower when using the ganirelix regimen (11.9\% for ganirelix vs $24.1 \%$ for triptorelin).

In a prospective randomized trial in 185 patients undergoing assisted reproductive technologies Wilcox et al. [70] compared a single injection of cetrorelix (3 mg) with a daily dose of $0.25 \mathrm{mg}$ of ganirelix in a flexible protocol. Cetrorelix and ganirelix were found to be equally effective; no patient in either treatment group had a premature LH surge and there were no statistically significant differences between treatments for any IVF/ICSI outcomes, including pregnancy rates. Cetrorelix is also available as a multipledose regimen $(0.25 \mathrm{mg}$ daily). Hsieh et al. [71] reported that the minimum effective dose of cetrorelix for pituitary suppression is $0.25 \mathrm{mg}$, resulting in comparable pregnancy rates. Olivennes et al. [65] showed that the multiple-dose regimen of cetrorelix ( $0.25 \mathrm{mg}$ daily) offers equal efficacy and safety to the single-dose regimen $(3 \mathrm{mg})$. Similar efficacy and safety results were shown in a cetrorelix $(0.25$ mg daily) or buserelin protocol [21].

\section{Flexible versus fixed dosing}

Flexible dosing was introduced to reduce the number of antagonist injections and the duration of stimulation. It is recommended that fixed dosing is started from day 5 or 6 of stimulation [72,73] while flexible dosing starts when the follicles reach a size of $>14 \mathrm{~mm}$ [74-76]. It has been suggested that development of flexible dosing regimens, that is, individualizing or tailoring GnRH antagonist administration, might lead to better clinical outcomes in $\mathrm{GnRH}$ antagonist-treated patients [77]. Results from several clinical studies support the efficacy and safety of flexible-dosing regimens with ganirelix, though some show no significant advantage over the standard fixed-dose regimen [78-80].

Nevertheless, there is evidence that flexible dosing regimens lead to improvement in the outcomes of ovarian stimulation cycles. In a prospective, randomized, singlecenter study comparing fixed multiple-dose antagonist with a flexible ganirelix regimen, Ludwig et al. [75] showed an improved outcome when a tailored rather than a standardized fixed protocol was used to schedule the start of the GnRH antagonist; a higher yield of oocytes was achieved despite less rFSH used. There were, however, no differences in pregnancy rates among the three groups.

The benefits of flexible GnRH antagonist administration according to follicular size versus starting dosing on a fixed day were also highlighted by Al-Inany et al. [81] in a metaanalysis of four randomized trials. Although no statistically significant difference in pregnancy rate was observed between flexible and fixed protocols, there was a significant reduction in the amount of $\mathrm{rFSH}$ with the flexible protocol.

\section{Use with GnRH agonist trigger}

Ovulation can either be induced with a bolus injection of hCG or a GnRH agonist. An advantage of using a 
GnRH agonist to trigger final oocyte maturation is the potential reduction in the risk of OHSS [22]. As an effective alternative to hCG-induced ovulation, $\mathrm{GnRH}$ agonists induce a sustained release of LH (and FSH) from the pituitary that effectively induces oocyte maturation and ovulation. A possible advantage of a GnRH agonist for trigger in comparison with hCG is the simultaneous induction of a FSH surge comparable to the surge of a natural cycle [82]. GnRH agonist triggering, however, results in a shorter endogenous LH surge that leads to a defective corpus luteum formation and an inadequate luteal phase $[83,84]$. The profound luteolysis observed after $\mathrm{GnRH}$ agonist triggering in contrast to the prolonged luteotropic effect often seen after triggering with hCG has been shown to almost completely eliminate the risk of OHSS in high responders, avoiding the need for cycle cancellation $[82,85]$. Because of the inadequate luteal phase after $\mathrm{GnRH}$ agonist trigger, the use of standard luteal phase support is inadequate and results in lower conception and higher miscarriage rates [86]. Therefore, luteal support strategies including one bolus of low-dose hCG, repeated boluses of hCG, recombinant LH add-back, and more intensive estradiol and progesterone supplementation were proposed to achieve optimal conception rates [82,87-89].

Engmann et al. [87] showed that this approach was effective in a clinical study in which 66 patients at high risk for developing OHSS were randomized to an ovarian stimulation protocol consisting of either a GnRH agonist trigger after co-treatment with ganirelix or a control group that received hCG trigger after dual pituitary suppression with birth control pills and a GnRH agonist. None of the patients receiving ganirelix developed OHSS compared with $31 \%$ of the patients in the control group. The study also found no significant differences in the rates of implantation (36.0\% with ganirelix vs $31.0 \%$ with control), clinical pregnancy $(56.7 \%$ vs $51.7 \%)$, and ongoing pregnancy (53.3\% vs $48.3 \%)$. In concluding, the authors suggested that a protocol consisting of a GnRH agonist trigger after $\mathrm{GnRH}$ antagonist co-treatment combined with luteal phase and early pregnancy estradiol and progesterone supplementation should be given strong consideration for patients at high risk of developing OHSS

In a more recent publication reviewing the predictive factors of successful outcome after $\mathrm{GnRH}$ agonist trigger and intensive luteal support, Kummer et al. [90] identified serum LH on the day of trigger and peak estradiol levels $\geq 4000 \mathrm{pg} / \mathrm{ml}$ as the most important predictors of success. Women with peak estradiol $\geq 4000 \mathrm{pg} / \mathrm{ml}$ had a significantly higher clinical pregnancy rate than women with peak estradiol $<4000 \mathrm{pg} / \mathrm{ml}$ after $\mathrm{GnRH}$ agonist trigger $(53.6 \%$ vs $38.1 \%$ ) [90]. The same group of investigators subsequently reported that a dual trigger of final oocyte maturation with a GnRH agonist and low-dose
hCG (1000 IU) resulted in improved implantation, clinical pregnancy, and live birth rates compared with a GnRH agonist alone, without increasing the risk of clinically significant OHSS in patients with peak estradiol levels $<4000 \mathrm{pg} / \mathrm{ml}$ [91].

Griesinger et al. [92] investigated the effect of cryopreservation of all two pronuclei-stage zygotes following GnRH agonist trigger on the incidence of severe OHSS and ongoing pregnancy rate in a prospective, observational, proof-of-concept study. The ongoing pregnancy rate was $36.8 \%$ (95\% confidence interval 19.1-59.0). No patients developed moderate or severe OHSS [92].

\section{LH add-back}

Despite the advantages of $\mathrm{GnRH}$ antagonists-that is, much shorter treatment regimens, fewer injections, and the need for less gonadotropin-the more general acceptance of antagonist regimens has been hampered by their perceived association with slightly lower pregnancy and implantation rates compared with $\mathrm{GnRH}$ agonist protocols.

Results from early studies suggested that low implantation rates were due to high daily doses of $\mathrm{GnRH}$ antagonists (0.5, 1, or $2 \mathrm{mg}$ once daily) inducing a sharp decrease in serum LH concentrations during the follicular phase of ovarian stimulation [93,94]. Supplementation with exogenous recombinant human LH (rLH) was suggested as an alternative to counter the consequences of LH depletion. In an RCT that included 60 patients, Garcia-Velasco et al. [95] employed an innovative protocol in which the pituitary response was suppressed with high-dose GnRH antagonist and rLH was added back to correct the diminished implantation rate. GnRH antagonist treatment $(2 \mathrm{mg} / \mathrm{d})$ was initiated on day 6 of stimulation together with 375 IU rLH, and maintained until the day of hCG administration, while control subjects received the standard dose of $0.25 \mathrm{mg} / \mathrm{d}$. Fluctuating LH concentrations were present on days 3 and 6 in both groups. This fluctuation continued on day 8 and on the day of hCG administration in the control (low-dose) group, where $30 \%$ of patients had LH concentrations $<1 \mathrm{IU} / \mathrm{L}$ on the hCG day. The study (high-dose) group showed stable LH concentrations on day 8 and on the hCG day, with no LH surges. No clinical differences in outcomes were found between the treatment groups. The LH add-back strategy (375 IU/d) appeared to "rescue" the adverse effects that high doses of GnRH antagonist have been seen to impose on implantation.

More recently, Bosch et al. [96] assessed the impact of LH add-back on cycle outcome during ovarian stimulation with GnRH antagonists in an RCT performed in two age subgroups $\leq 35$ years $(\mathrm{n}=380)$ and $36-39$ years ( $\mathrm{n}=340)$. $\mathrm{rLH}$ administration significantly increased the implantation rate in the older population, and a clinically relevant (although not statistically significant) better 
ongoing pregnancy rate per cycle was observed. Interestingly, no benefit from rLH administration was demonstrated in patients younger than 36 years.

\section{Use with and without oral contraceptives}

Oral contraceptive pill pretreatment in $\mathrm{GnRH}$ antagonist cycles has been advocated for scheduling ovarian stimulation and oocyte retrieval in IVF programs. An RCT, by Rombauts et al. [97], assessed the impact of oral contraceptive scheduling with a ganirelix regimen on the ovarian response of women undergoing rFSH stimulation for IVF, compared with a nonscheduled ganirelix regimen and a long GnRH agonist (nafarelin) protocol. The study found that in the three groups the number of oocytes retrieved and the number of good-quality embryos were similar. Evidence from several other RCTs in the literature supports the use of oral contraceptive scheduling and shows that success rates are the same [98,99], although it has been found that after oral contraceptive pretreatment it may take an extra day to stimulate [100]. In the most recent Cochrane review, a subgroup analysis of 10 RCTs that used oral contraceptives pretreatment showed that there were no significant differences in ongoing pregnancy rates in $\mathrm{GnRH}$ antagonist protocols compared with $\mathrm{GnRH}$ agonist protocols [45].

Conversely, Griesinger et al. [101] showed a statistically significant reduction in the likelihood of ongoing pregnancy with oral contraceptive pretreatment when a pill-free interval of 2-5 days is used before starting gonadotropin stimulation in a meta-analysis of six RCTs on oral contraceptive pretreatment in GnRH antagonist IVF cycles involving 1343 patients. The negative effect of the oral contraceptive pretreatment on the IVF outcome may be explained by the fact that some of the studies included in the meta-analysis [101] started ovarian stimulation 2-3 days after the last oral contraceptive pill rather than 5 days later.

More research is needed to determine the most reliable and efficacious way to schedule GnRH antagonist stimulation cycles with oral contraceptive pretreatment.

\section{Use with and without estrogen pretreatment}

Estrogen pretreatment in GnRH antagonist cycles has also been suggested as an alternative method to achieve gonadotropin suppression during the early follicular phase so that scheduling ovarian stimulation and oocyte retrieval in IVF programs can be planned. Guivarc'h-Levêque et al. [102] found that estrogen pretreatment was safe in a large prospective study of patients undergoing IVF/ICSI. A greater requirement of $\mathrm{FSH}$ and a longer duration of stimulation were associated with estrogen pretreatment [103,104]. However estrogen pretreatment did not affect the IVF/ICSI outcomes [103].

\section{Decreasing OHSS with GnRH antagonists}

OHSS is a preventable condition and implementing evidence-based prevention strategies should enable clinicians to reduce its occurrence. As we have discussed, $\mathrm{GnRH}$ antagonist protocols and the use of a GnRH agonist to trigger final oocyte maturation in a $\mathrm{GnRH}$ antagonist protocol are two treatment strategies that could reduce or prevent OHSS, especially when used in conjunction.

Significantly elevated or rapidly rising serum estradiol concentrations are known to predispose patients to development of OHSS. Therefore, since GnRH antagonist treatment is associated with reduced estradiol concentrations, it might be expected to decrease the risk of OHSS [105]. Gustofson et al. [105] showed that ganirelix treatment rapidly reduced circulating estradiol concentrations without adversely affecting oocyte maturation, fertilization rates, or embryo quality and resulted in a high pregnancy rate in the subgroup of women with ovarian hyperresponse who were pretreated with a GnRH agonist. Despite the treatment cohort being at high risk of developing OHSS, only two cases of severe OHSS occurred. The RCT by Lainas et al. [106] provided further evidence to support the use of GnRH antagonists among patients at risk of OHSS. This study compared a flexible GnRH antagonist protocol with the long $\mathrm{GnRH}$ agonist down-regulation protocol in 220 patients with polycystic ovary syndrome (PCOS). While pregnancy rates were similar in the two protocols, the GnRH antagonist protocol was associated with a significantly lower incidence of OHSS.

The reduction in the incidence of OHSS with GnRH antagonist protocols was shown in the Cochrane review of 27 RCTs in 2006 [107] and 29 RCTs in 2011 [45]. These systematic reviews compared $\mathrm{GnRH}$ antagonists (ganirelix or cetrorelix) with the long protocol of $\mathrm{GnRH}$ agonist. A statistically significant reduction in the incidence of severe OHSS with the antagonist protocol (27 RCTs: relative risk ratio, $0.61 ; 95 \%$ confidence interval, $0.42-0.89 ; P=0.01$ [107]; 29 RCTs: odds ratio $0.43,95 \%$ confidence interval 0.33-0.57 [45]) was observed. In addition, interventions to prevent OHSS, such as coasting and cycle cancellation, were administered more frequently in the agonist group (27 RCTs: odds ratio, 0.44; 95\% confidence interval, $0.21-$ 0.93; $P=0.03$ [107]; 29 RCTs: odds ratio, $0.50,95 \%$ confidence interval, $0.33-0.76 ; P=0.001$ [45]). In a metaanalysis of 7 RCTs, Xiao et al. [108] showed that the rate of OHSS was significantly lower in the GnRH antagonist group than the $\mathrm{GnRH}$ agonist group in women with PCOS (odds ratio $0.36,95 \%$ confidence interval 0.25-0.52).

Alternatively, the risk of OHSS can be reduced by triggering final oocyte maturation with a GnRH agonist. The reduction of the risk of OHSS using a GnRH agonist trigger has been discussed above.

Another new method of tertiary prevention of earlyonset OHSS using GnRH antagonists has been reported 
by Lainas and colleagues [109]. Antagonist administration was re-initiated at a daily dose of $0.25 \mathrm{mg}$ after patients developed early OHSS, and continued daily for a week, while all embryos were cryopreserved. No progression of severe early OHSS was observed in any of the patients and none of the patients required hospitalization.

\section{Neonatal outcomes}

Long-term outcomes after GnRH antagonist treatment do not differ from those observed with GnRH agonist regimens. Obstetrical and neonatal data on 839 pregnancies, resulting in 969 live-born infants after ganirelix treatment were compared with a historical cohort of 753 pregnancies after long GnRH agonist (buserelin) treatment, resulting in 963 live-born infants [110]. There were no differences in maternal characteristics, fertilization method, and pregnancy and delivery complications between the ganirelix and historical GnRH agonist groups. Women experienced more multiple pregnancies in the historical GnRH agonist group (31.9\%) than the ganirelix group $(18.7 \% ; P<0.0001)$, and both groups were comparable with respect to pregnancy loss after 16 weeks' gestation. The incidence of major congenital malformations in fetuses with gestational age $\geq 26$ weeks was $5.0 \%$ in the ganirelix cohort versus $5.4 \%$ in the historical GnRH agonist group (odds ratio, 0.94; 95\% confidence interval, 0.62-1.42).

Boerrigter et al. [111] conducted a pooled analysis of all follow-up data of the phase 2 and 3 trials for the development of ganirelix. Data on 340 ongoing pregnancies and neonatal outcomes for 432 children showed that there were no differences between the GnRH antagonist and GnRH agonist regimens with respect to pregnancy loss after 16 weeks' gestation, and the incidence and nature of complications during pregnancy and delivery did not differ between the two groups [111]. No major differences were observed in neonatal characteristics of infants in the ganirelix and agonist groups, who had an overall mean birth weight on average of $3200 \mathrm{~g}$ for singletons, $2300 \mathrm{~g}$ for twins, and 1800-1900 g for triplets. Congenital malformations were observed in 32 of 424 (7.5\%) fetuses in the ganirelix group and in 10 of 181 $(5.5 \%)$ in the agonist group.

\section{Conclusions}

We reviewed the scientific literature on the use of GnRH antagonists, concentrating on the most recently available evidence. Antagonist treatment protocols are a viable alternative to agonist treatment. The multiple-dose protocol is effective in the prevention of premature LH surge. Compared with the long agonist protocol, GnRH antagonist treatment is shorter, rapidly absorbed, rapidly reversible, requires fewer injections, and appears to require a lower amount of gonadotropins, which is likely to lead to improved patient compliance and lower costs. The lower

\section{Table 2 Suitable candidates for GnRH antagonist} treatment

\author{
Patient populations benefiting from GnRH antagonist protocols \\ - $\quad$ Patients undergoing first-line controlled ovarian stimulation [8,59] \\ - $\quad$ Patients who have not responded to other controlled ovarian \\ stimulation regimens, including those with gonadotropin-releasing \\ hormone agonist [113] \\ - $\quad$ Patients with a poor prognosis [12] \\ - $\quad$ Oocyte donors [17] \\ - $\quad$ Patients at risk for ovarian hyperstimulation syndrome $[93,105]$ \\ - $\quad$ Patients with polycystic ovarian syndrome [114] \\ - $\quad$ Patients taking oral contraceptive to regulate menstrual cycles [97]
}

pregnancy rate reported in some early RCTs has been offset by the findings of subsequent meta-analyses, and this is probably the result of optimization of the antagonist treatment protocol. The only contraindications to the use of $\mathrm{GnRH}$ antagonists for the inhibition of premature $\mathrm{LH}$ surges in women undergoing controlled ovarian stimulation are hypersensitivity to $\mathrm{GnRH}$ antagonists or pregnancy [112]. GnRH antagonists have been used safely and effectively in a wide range of patients (Table 2), such as those undergoing first-line controlled ovarian stimulation [8], those with a poor prognosis [12], and patients taking oral contraceptives to regulate menstrual cycles [97]. The antagonist flexible-dosing regimen has also shown promise among women diagnosed with PCOS [114]. Certain other patient populations might particularly benefit from ganirelix protocols, such as patients who have not responded to other controlled ovarian hyperstimulation regimens (including those with GnRH agonist) [113] or, to the other extreme, patients with a high risk of developing OHSS $[93,105]$. There are no adverse effects associated with a GnRH antagonist protocol on assisted reproductive technology outcomes. Due to the ability to trigger final oocyte maturation with a GnRH agonist to prevent OHSS, antagonist protocols are becoming the treatment of choice for ovarian stimulation of oocyte donors [17].

Overall, GnRH antagonist treatment protocols are effective, easy to use, allow flexibility of treatment and, therefore, appear to offer a promising alternative to the long-established GnRH agonist regimens for prevention of a premature LH surge during ovarian stimulation for assisted reproductive techniques.

\section{Competing interests}

$A B C$ has received payments for speakers' bureaus from Schering-Plough, EMD Serono, and Ferring. CB has received payments for lectures from Merck.

\section{Authors' contributions}

$A B C$ and $C B$ participated in the drafting of the manuscript and contributed to the critical discussion. Both authors gave final approval of the version to be published. 


\section{Acknowledgements}

Financial support was provided by Merck, Sharpe \& Dohme Corp., a subsidiary of Merck \& Co., Inc., Whitehouse Station, NJ. Medical writing and editorial assistance was provided by Christina Campbell, PhD, of PAREXEL UK This assistance was funded by Merck, Sharp \& Dohme Corp., a subsidiary of Merck \& Co., Inc., Whitehouse Station, NJ.

\section{Author details}

${ }^{1}$ Mount Sinai Medical Center, New York, NY, USA. ${ }^{2}$ Reproductive Medicine Associates of New York, New York, NY, USA. ${ }^{3}$ The Center for Advanced Reproductive Services, Department of Ob/Gyn, University of Connecticut, Farmington, CT, USA.

Received: 14 December 2012 Accepted: 27 February 2013

Published: 15 March 2013

\section{References}

1. Edwards RG, Lobo R, Bouchard P: Time to revolutionize ovarian stimulation. Hum Reprod 1996, 11:917-919.

2. Janssens RM, Lambalk CB, Vermeiden JP, Schats R, Bernards JM, RekersMombarg LT, Schoemaker J: Dose-finding study of triptorelin acetate for prevention of a premature LH surge in IVF: a prospective, randomized, double-blind, placebo-controlled study. Hum Reprod 2000, 15:2333-2340.

3. Templeton A, Morris JK, Parslow W: Factors that affect outcome of in-vitro fertilisation treatment. Lancet 1996, 348:1402-1406.

4. Fleming R, Adam AH, Barlow DH, Black WP, MacNaughton MC, Coutts JR: A new systematic treatment for infertile women with abnormal hormone profiles. Br J Obstet Gynecol 1982, 89:80-83.

5. Huirne JA, Homburg R, Lambalk CB: Are GnRH antagonists comparable to agonists for use in IVF? Hum Reprod 2007, 22:2805-2813.

6. Ron-El R, Raziel A, Schachter M, Strassburger D, Kasterstein E, Friedler S: Induction of ovulation after gnRH antagonists. Hum Reprod Update 2000, 6:318-321

7. Gordon K, Hodgen GD: GnRH agonists and antagonists in assisted reproduction. Baillieres Clin Obstet Gynaecol 1992, 6:247-265.

8. Borm G, Mannaerts B: Treatment with the gonadotrophin-releasing hormone antagonist ganirelix in women undergoing ovarian stimulation with recombinant follicle stimulating hormone is effective, safe and convenient: results of a controlled, randomized, multicentre trial. The European Orgalutran Study Group. Hum Reprod 2000, 15:1490-1498.

9. Al-Inany $\mathrm{H}$, Aboulghar $\mathrm{M}: \mathrm{GnRH}$ antagonist in assisted reproduction: a Cochrane review. Hum Reprod 2002, 17:874-885.

10. Gillies PS, Faulds D, Balfour JA, Perry CM: Ganirelix. Drugs 2000, 59:107-111.

11. Engel JB, Rieger $L$, Dietl J, Hönig A: The GnRH antagonist cetrorelix: established indications and future potential. Expert Rev Obstet Gynecol 2007, 2:431-440.

12. Shapiro DB, Mitchell-Leef D, Carter M, Nagy ZP: Ganirelix acetate use in normal- and poor-prognosis patients and the impact of estradiol patterns. Fertil Steril 2005, 83:666-670

13. Shapiro DB, Mitchell-Leef D: GnRH antagonist in in vitro fertilization: where we are now. Minerva Ginecol 2003, 55:373-388.

14. Tarlatzis BC, Kolibianakis EM: GnRH agonists vs antagonists. Best Pract Res Clin Obstet Gynaecol 2007, 21:57-65.

15. Badrawi A, Al-Inany H, Hussein M, Zaki S, Ramzy A: Agonist vs. antagonist in ICSI cycles: a randomized trial and cost-effectiveness analysis. Middle East Fertil Soc J 2005, 10:49-54.

16. Kamath MS, Mangalraj AM, Muthukumar KM, George K: Gonadotrophin releasing hormone antagonist in IVF/ICSI. J Hum Reprod Sci 2008, 1:29-32.

17. Bodri D, Sunkara SK, Coomarasamy A: Gonadotropin-releasing hormone agonists versus antagonists for controlled ovarian hyperstimulation in oocyte donors: a systematic review and meta-analysis. Fertil Steril 2011, 95:164-169.

18. The Practice Committee of the American Society for Reproductive Medicine: Ovarian hyperstimulation syndrome. Fertil Steril 2008, 90:S188-S193.

19. Humaidan P, Quartarolo J, Papanikolaou EG: Preventing ovarian hyperstimulation syndrome: guidance for the clinician. Fertil Steril 2010, 94:389-400.

20. Tarlatzis BC, Fauser BC, Kolibianakis EM, Diedrich K, Rombauts L, Devroey P: $\mathrm{GnRH}$ antagonists in ovarian stimulation for IVF. Hum Reprod Update 2006, 12:333-340.
21. Huirne JA, Hugues JN, Pirard C, Fischl F, Sage JC, Pouly JL, Obruca A, Braat DM, van Loenen AC, Lambalk CB: Cetrorelix in an oral contraceptivepretreated stimulation cycle compared with buserelin in IVF/ICSI patients treated with $\mathrm{r}$-hFSH: a randomized, multicentre, phase IIIb study. Hum Reprod 2006, 21:1408-1415.

22. Devroey P, Aboulghar M, Garcia-Velasco J, Griesinger G, Humaidan P Kolibianakis E, Ledger W, Tomas C, Fauser BC: Improving the patient's experience of IVF/ICSI: a proposal for an ovarian stimulation protocol with GnRH antagonist co-treatment. Hum Reprod 2009, 24:764-774.

23. Kolibianakis EM, Collins J, Tarlatzis BC, Devroey P, Diedrich K, Griesinger G: Among patients treated for IVF with gonadotrophins and $\mathrm{GnRH}$ analogues, is the probability of live birth dependent on the type of analogue used? A systematic review and meta-analysis. Hum Reprod Update 2006, 12:651-671.

24. Tur-Kaspa I, Ezcurra D: GnRH antagonist, cetrorelix, for pituitary suppression in modern, patient-friendly assisted reproductive technology. Expert Opin Drug Metab Toxicol 2009, 5:1323-1336.

25. Albano C, Felberbaum RE, Smitz J, Riethmuller-Winzen H, Engel J, Diedrich K, Devroey P: Ovarian stimulation with HMG: results of a prospective randomized phase III European study comparing the luteinizing hormone-releasing hormone (LHRH)-antagonist cetrorelix and the LHRHagonist buserelin. European Cetrorelix Study Group. Hum Reprod 2000, 15:526-531.

26. Olivennes F, Belaisch-Allart J, Emperaire JC, Dechaud H, Alvarez S, Moreau L, Nicollet B, Zorn JR, Bouchard P, Frydman R: Prospective, randomized, controlled study of in vitro fertilization-embryo transfer with a single dose of a luteinizing hormone-releasing hormone (LH-RH) antagonist (cetrorelix) or a depot formula of an LH-RH agonist (triptorelin). Fertil Steril 2000, 73:314-320

27. Fluker M, Grifo J, Leader A, Levy M, Meldrum D, Muasher SJ, Rinehart J, Rosenwaks Z, Scott RT Jr, Schoolcraft W, Shapiro DB: Efficacy and safety of ganirelix acetate versus leuprolide acetate in women undergoing controlled ovarian hyperstimulation. Fertil Steril 2001, 75:38-45.

28. The European and Middle East Orgalutran Study Group: Comparable clinical outcome using the $\mathrm{GnRH}$ antagonist ganirelix or a long protocol of the $\mathrm{GnRH}$ agonist triptorelin for the prevention of premature $\mathrm{LH}$ surges in women undergoing ovarian stimulation. Hum Reprod 2001 16:644-651

29. Akman MA, Erden HF, Tosun SB, Bayazit N, Aksoy E, Bahceci M: Comparison of agonistic flare-up-protocol and antagonistic multiple dose protocol in ovarian stimulation of poor responders: results of a prospective randomized trial. Hum Reprod 2001, 16:868-870

30. Hohmann FP, Macklon NS, Fauser BC: A randomized comparison of two ovarian stimulation protocols with gonadotropin-releasing hormone $(\mathrm{GnRH})$ antagonist cotreatment for in vitro fertilization commencing recombinant follicle-stimulating hormone on cycle day 2 or 5 with the standard long GnRH agonist protocol. J Clin Endocrinol Metab 2003, 88:166-173.

31. Martinez F, Coroleu B, Marques L, Parera N, Buxaderas R, Tur R, Barri PN: Comparación del "Protocolo Corto" versus "Antagonistas" con o sin Citrato de Clomifeno para estimulación en FIV de pacientes con "baja respuesta". Rev Ibero Am Fertil 2003:2025-2360.

32. Franco JG Jr, Baruffi LRL, Petersen CG, Mauri CG, Felipe V, Contart P: Comparison of ovarian stimulation with recombinant FSH after 2nd phase protocols with GnRH analogs (I-Estradiol + Ganirelix versus IINafarelin). J Brasileiro Reprod Assist 2003, 7:27-33.

33. Hwang JL, Seow KM, Lin YH, Huang LW, Hsieh BC, Tsai YL, Wu GJ, Huang SC, Chen CY, Chen PH, Tzeng CR: Ovarian stimulation by concomitant administration of cetrorelix acetate and HMG following Diane-35 pretreatment for patients with polycystic ovary syndrome: a prospective randomized study. Hum Reprod 2004, 19:1993-2000.

34. Sauer MV, Thornton MH, Schoolcraft W, Frishman GN: Comparative efficacy and safety of cetrorelix with or without mid-cycle recombinant $\mathrm{LH}$ and leuprolide acetate for inhibition of premature LH surges in assisted reproduction. Reprod Biomed Online 2004, 9:487-493.

35. Loutradis D, Stefanidis K, Drakakis P, Milingos S, Antsaklis A, Michalas S: A modified gonadotropin-releasing hormone $(\mathrm{GnRH})$ antagonist protocol failed to increase clinical pregnancy rates in comparison with the long GnRH protocol. Fertil Steril 2004, 82:1446-1448.

36. Check ML, Check JH, Choel JK, Davies E, Kiefer D: Effect of antagonists vs agonists on in vitro fertilization outcome. Clin Exp Obstet Gynecol 2004 31:257-259. 
37. Xavier P, Gamboa C, Calejo L, Silva J, Stevenson D, Nunes A, Martinez-de -Oliveira J: A randomised study of GnRH antagonist (cetrorelix) versus agonist (busereline) for controlled ovarian stimulation: effect on safety and efficacy. Eur J Obstet Gynecol Reprod Biol 2005, 120:185-189.

38. Malmusi S, La MA, Giulini S, Xella S, Tagliasacchi D, Marsella T, Volpe A: Comparison of a gonadotropin-releasing hormone $(\mathrm{GnRH})$ antagonist and $\mathrm{GnRH}$ agonist flare-up regimen in poor responders undergoing ovarian stimulation. Fertil Steril 2005, 84:402-406.

39. Marci R, Caserta D, Dolo V, Tatone C, Pavan A, Moscarini M: GnRH antagonist in IVF poor-responder patients: results of a randomized trial. Reprod Biomed Online 2005, 11:189-193.

40. Cheung LP, Lam PM, Lok IH, Chiu TT, Yeung SY, Tjer CC, Haines CJ: GnRH antagonist versus long $\mathrm{GnRH}$ agonist protocol in poor responders undergoing IVF: a randomized controlled trial. Hum Reprod 2005, 20:616-621.

41. Barmat LI, Chantilis SJ, Hurst BS, Dickey RP: A randomized prospective trial comparing gonadotropin-releasing hormone $(\mathrm{GnRH})$ antagonist/ recombinant follicle-stimulating hormone $(\mathrm{rFSH})$ versus $\mathrm{GnRH}$-agonist $/ \mathrm{rFSH}$ in women pretreated with oral contraceptives before in vitro fertilization. Fertil Steril 2005, 83:321-330.

42. Bahceci M, Ulug U, Ben-Shlomo I, Erden HF, Akman MA: Use of a GnRH antagonist in controlled ovarian hyperstimulation for assisted conception in women with polycystic ovary disease: a randomized, prospective, pilot study. J Reprod Med 2005, 50:84-90.

43. Schmidt DW, Bremner T, Orris JJ, Maier DB, Benadiva CA, Nulsen JC: A randomized prospective study of microdose leuprolide versus ganirelix in in vitro fertilization cycles for poor responders. Fertil Steril 2005, 83:1568-1571.

44. Lee TH, Wu MY, Chen HF, Chen MJ, Ho HN, Yang YS: Ovarian response and follicular development for single-dose and multiple-dose protocols for gonadotropin-releasing hormone antagonist administration. Fertil Steril 2005, 83:1700-1707.

45. Al-Inany HG, Youssef MA, Aboulghar M, Broekmans F, Sterrenburg M, Smit J, Abou-Setta AM: Gonadotrophin-releasing hormone antagonists for assisted reproductive technology. Cochrane Database Syst Rev 2011, 5:CD001750

46. Heijnen EM, Eijkemans MJ, De Klerk C, Polinder S, Beckers NG, Klinkert ER, Broekmans FJ, Passchier J, Te Velde ER, Macklon NS, Fauser BC: A mild treatment strategy for in-vitro fertilisation: a randomised non-inferiority trial. Lancet 2007, 369:743-749.

47. Huirne JA, van Loenen AC, Donnez J, Pirard C, Homburg R, Schats R, McDonnell J, Lambalk CB: Effect of an oral contraceptive pill on follicular development in IVF/ICSI patients receiving a GnRH antagonist: a randomized study. Reprod Biomed Online 2006, 13:235-245.

48. Kim CH, Jeon GH, Cheon YP, Jeon I, Kim SH, Chae HD, Kang BM: Comparison of $\mathrm{GnRH}$ antagonist protocol with or without oral contraceptive pill pretreatment and GnRH agonist low-dose long protocol in low responders undergoing IVF/intracytoplasmic sperm injection. Fertil Steril 2009, 92:1758-1760.

49. Kurzawa R, Ciepiela P, Baczkowski T, Safranow K, Brelik P: Comparison of embryological and clinical outcome in $\mathrm{GnRH}$ antagonist vs. $\mathrm{GnRH}$ agonist protocols for in vitro fertilization in PCOS non-obese patients. A prospective randomized study. J Assist Reprod Genet 2008, 25:365-374.

50. Lin YH, Hwang JL, Seow KM, Huang LW, Hsieh BC, Tzeng CR: Comparison of outcome of clomiphene citrate/human menopausal gonadotropin/ cetrorelix protocol and buserelin long protocol-a randomized study. Gynecol Endocrinol 2006, 22:297-302.

51. Ye H, Huang GN, Zeng PH, Pei L: IVF/ICSI outcomes between cycles with luteal estradiol (E2) pretreatment before GnRH antagonist protocol and standard long GnRH agonist protocol: a prospective and randomized study. J Assist Reprod Genet 2009, 26:105-111.

52. Akman MA, Erden HF, Tosun SB, Bayazit N, Aksoy E, Bahceci M: Addition of $\mathrm{GnRH}$ antagonist in cycles of poor responders undergoing IVF. Hum Reprod 2000, 15:2145-2147

53. Sunkara SK, Tuthill J, Khairy M, El Toukhy T, Coomarasamy A, Khalaf Y, Braude P: Pituitary suppression regimens in poor responders undergoing IVF treatment: a systematic review and meta-analysis. Reprod Biomed Online 2007, 15:539-546.

54. Franco JG Jr, Baruffi RL, Mauri AL, Petersen CG, Felipe V, Cornicelli J, Cavagna M, Oliveira JB: GnRH agonist versus GnRH antagonist in poor ovarian responders: a meta-analysis. Reprod Biomed Online 2006, 13:618-627.
55. Prapas N, Prapas $Y$, Panagiotidis $Y$, Prapa S, Vanderzwalmen $P$, Schoysman $R$, Makedos G: GnRH agonist versus GnRH antagonist in oocyte donation cycles: a prospective randomized study. Hum Reprod 2005, 20:1516-1520.

56. Tur-Kaspa I, Cohen A, Tkachenko N, Fowler M, Bernal A, Verlinsky Y: GnRH antagonist (cetrotide) instead of agonist to prepare recipients for embryo transfer: a prospective, randomized, controlled trial [abstract]. Fertil Steril 2008, 90:S382.

57. Kosmas IP, Tatsioni A, Kolibianakis EM, Verpoest W, Tournaye H, der EJ V, Devroey P: Effects and clinical significance of GnRH antagonist administration for IUI timing in FSH superovulated cycles: a metaanalysis. Fertil Steril 2008, 90:367-372.

58. Prapas N, Tavaniotou A, Panagiotidis Y, Prapa S, Kasapi E, Goudakou M Papatheodorou A, Prapas Y: GnRH antagonists and endometrial receptivity in oocyte recipients: a prospective randomized trial. Reprod Biomed Online 2009, 18:276-281.

59. Johnston-MacAnanny EB, DiLuigi AJ, Engmann LL, Maier DB, Benadiva CA, Nulsen JC: Selection of first in vitro fertilization cycle stimulation protocol for good prognosis patients: gonadotropin releasing hormone antagonist versus agonist protocols. J Reprod Med 2011, 56:12-16.

60. Copperman AB: Antagonists in poor-responder patients. Fertil Steril 2003, 80(Suppl 1):S16-S24.

61. Pu D, Wu J, Liu J: Comparisons of GnRH antagonist versus GnRH agonist protocol in poor ovarian responders undergoing IVF. Hum Reprod 2011, 26:2742-2749.

62. Dragisic KG, Davis OK, Fasouliotis SJ, Rosenwaks Z: Use of a luteal estradiol patch and a gonadotropin-releasing hormone antagonist suppression protocol before gonadotropin stimulation for in vitro fertilization in poor responders. Fertil Steril 2005, 84:1023-1026.

63. Weitzman VN, Engmann L, DiLuigi A, Maier D, Nulsen J, Benadiva C: Comparison of luteal estradiol patch and gonadotropin-releasing hormone antagonist suppression protocol before gonadotropin stimulation versus microdose gonadotropin-releasing hormone agonist protocol for patients with a history of poor in vitro fertilization outcomes. Fertil Steril 2009, 92:226-230.

64. DiLuigi AJ, Engmann L, Schmidt DW, Benadiva CA, Nulsen JC: A randomized trial of microdose leuprolide acetate protocol versus luteal phase ganirelix protocol in predicted poor responders. Fertil Steril 2011, 95:2531-2533.

65. Olivennes F, Diedrich K, Frydman R, Felberbaum RE, Howles CM: Safety and efficacy of a $3 \mathrm{mg}$ dose of the $\mathrm{GnRH}$ antagonist cetrorelix in preventing premature LH surges: report of two large multicentre, multinational, phase IIIb clinical experiences. Reprod Biomed Online 2003, 6:432-438.

66. Olivennes F, Fanchin R, Bouchard P, de Ziegler D, Taieb J, Selva J, Frydman $R$ : The single or dual administration of the gonadotropin-releasing hormone antagonist Cetrorelix in an in vitro fertilization-embryo transfer program. Fertil Steril 1994, 62:468-476.

67. Vlaisavljevic V, Reljic M, Lovrec VG, Kovacic B: Comparable effectiveness using flexible single-dose $\mathrm{GnRH}$ antagonist (cetrorelix) and single-dose long GnRH agonist (goserelin) protocol for IVF cycles-a prospective, randomized study. Reprod Biomed Online 2003, 7:301-308.

68. Dal Prato L, Borini A: Use of antagonists in ovarian stimulation protocols. Reprod Biomed Online 2005, 10:330-338.

69. The Ganirelix dose-finding study group: A double-blind, randomized, dose-finding study to assess the efficacy of the gonadotrophin-releasing hormone antagonist ganirelix (Org 37462) to prevent premature luteinizing hormone surges in women undergoing ovarian stimulation with recombinant follicle stimulating hormone (Puregon). Hum Reprod 1998, 13:3023-3031.

70. Wilcox J, Potter D, Moore M, Ferrande L, Kelly E: Prospective, randomized trial comparing cetrorelix acetate and ganirelix acetate in a programmed, flexible protocol for premature luteinizing hormone surge prevention in assisted reproductive technologies. Fertil Steril 2005, 84:108-117.

71. Hsieh YY, Chang CC, Tsai HD: Comparisons of different dosages of gonadotropin-releasing hormone $(\mathrm{GnRH})$ antagonist, short-acting form and single, half-dose, long-acting form of GnRH agonist during controlled ovarian hyperstimulation and in vitro fertilization. Taiwan J Obstet Gynecol 2008, 47:66-74.

72. Devroey P, Boostanfar R, Koper NP, Mannaerts BM, ljzerman-Boon PC, Fauser $\mathrm{BC}$ : A double-blind, non-inferiority RCT comparing corifollitropin alfa and recombinant FSH during the first seven days of ovarian stimulation using a GnRH antagonist protocol. Hum Reprod 2009, 24:3063-3072. 
73. Nyboe Andersen A, Witjes H, Gordon K, Mannaerts B: Predictive factors of ovarian response and clinical outcome after IVF/ICSI following a rFSH/ $\mathrm{GnRH}$ antagonist protocol with or without oral contraceptive pretreatment. Hum Reprod 2011, 26:3413-3423.

74. Depalo R, Jayakrishan K, Garruti G, Totaro I, Panzarino M, Giorgino F, Selvaggi LE: $\mathrm{GnRH}$ agonist versus $\mathrm{GnRH}$ antagonist in in vitro fertilization and embryo transfer (IVF/ET). Reprod Biol Endocrinol 2012, 10:26.

75. Ludwig M, Katalinic A, Banz C, Schroder AK, Loning M, Weiss JM, Diedrich K: Tailoring the $\mathrm{GnRH}$ antagonist cetrorelix acetate to individual patients' needs in ovarian stimulation for IVF: results of a prospective, randomized study. Hum Reprod 2002, 17:2842-2845

76. Mochtar $\mathrm{MH}$ : The effect of an individualized $\mathrm{GnRH}$ antagonist protocol on folliculogenesis in IVF/ICSI. Hum Reprod 2004, 19:1713-1718.

77. Felberbaum RE, Diedrich K: Gonadotrophin-releasing hormone antagonists: will they replace the agonists? Reprod Biomed Online 2003, 6:43-53.

78. Oberyé J, Study Group on Weight Adjusted Dosing of Ganirelix: No need for dose adjustment of GnRH antagonist based on patient's body weight in controlled ovarian hyperstimulation with recombinant follicle stimulating hormone. Fertil Steril 2003, 80(Suppl 3):S9.

79. Escudero E, Bosch E, Crespo J, Simon C, Remohi J, Pellicer A: Comparison of two different starting multiple dose gonadotropin-releasing hormone antagonist protocols in a selected group of in vitro fertilization-embryo transfer patients. Fertil Steril 2004, 81:562-566.

80. Kolibianakis EM, Venetis CA, Kalogeropoulou L, Papanikolaou E, Tarlatzis BC: Fixed versus flexible gonadotropin-releasing hormone antagonist administration in in vitro fertilization: a randomized controlled trial. Fertil Steril 2011, 95:558-562.

81. Al-Inany H, Aboulghar MA, Mansour RT, Serour Gl: Optimizing GnRH antagonist administration: meta-analysis of fixed versus flexible protocol. Reprod Biomed Online 2005, 10:567-570.

82. Humaidan P, Kol S, Papanikolaou EG: GnRH agonist for triggering of final oocyte maturation: time for a change of practice? Hum Reprod Update 2011, 17:510-524.

83. Humaidan $\mathrm{P}$, Bredkjaer HE, Bungum L, Bungum M, Grondahl ML, Westergaard L, Andersen CY: GnRH agonist (buserelin) or hCG for ovulation induction in GnRH antagonist IVF/ICSI cycles: a prospective randomized study. Hum Reprod 2005, 20:1213-1220.

84. Kolibianakis EM, Schultze-Mosgau A, Schroer A, van Steirteghem A, Devroey $P$, Diedrich K, Griesinger G: A lower ongoing pregnancy rate can be expected when GnRH agonist is used for triggering final oocyte maturation instead of HCG in patients undergoing IVF with GnRH antagonists. Hum Reprod 2005, 20:2887-2892.

85. Itskovitz-Eldor J, Kol S, Mannaerts B: Use of a single bolus of GnRH agonist triptorelin to trigger ovulation after $\mathrm{GnRH}$ antagonist ganirelix treatment in women undergoing ovarian stimulation for assisted reproduction, with special reference to the prevention of ovarian hyperstimulation syndrome: preliminary report: short communication. Hum Reprod 2000, 15:1965-1968.

86. Engmann L, Benadiva C: Agonist trigger: what is the best approach? Agonist trigger with aggressive luteal support. Fertil Steril 2012, 97:531-533.

87. Engmann L, DiLuigi A, Schmidt D, Nulsen J, Maier D, Benadiva C: The use of gonadotropin-releasing hormone $(\mathrm{GnRH})$ agonist to induce oocyte maturation after cotreatment with $\mathrm{GnRH}$ antagonist in high-risk patients undergoing in vitro fertilization prevents the risk of ovarian hyperstimulation syndrome: a prospective randomized controlled study. Fertil Steril 2008, 89:84-91.

88. Kol S, Humaidan P, Itskovitz-Eldor J: GnRH agonist ovulation trigger and hCG-based, progesterone-free luteal support: a proof of concept study. Hum Reprod 2011, 26:2874-2877.

89. Humaidan P, Papanikolaou EG, Kyrou D, Alsbjerg B, Polyzos NP, Devroey P, Fatemi HM: The luteal phase after $\mathrm{GnRH}$-agonist triggering of ovulation: present and future perspectives. Reprod Biomed Online 2012, 24:134-141.

90. Kummer N, Benadiva C, Feinn R, Mann J, Nulsen J, Engmann L: Factors that predict the probability of a successful clinical outcome after induction of oocyte maturation with a gonadotropin-releasing hormone agonist. Fertil Steril 2011, 96:63-68.

91. Griffin D, Benadiva C, Kummer N, Budinetz T, Nulsen J, Engmann L: Dual trigger of oocyte maturation with gonadotropin-releasing hormone agonist and low-dose human chorionic gonadotropin to optimize live birth rates in high responders. Fertil Steril 2012, 97:1316-1320.
92. Griesinger G, Von OS, Schroer A, Ludwig AK, Diedrich K, Al-Hasani S, Schultze-Mosgau A: Elective cryopreservation of all pronuclear oocytes after GnRH agonist triggering of final oocyte maturation in patients at risk of developing OHSS: a prospective, observational proof-of-concept study. Hum Reprod 2007, 22:1348-1352.

93. Al-Inany $\mathrm{H}$, Aboulghar M: Gonadotrophin-releasing hormone antagonists for assisted conception. Cochrane Database Syst Rev 2001, 4:CD001750.

94. Gordon K: Gonadotropin-releasing hormone antagonists implications for oocyte quality and uterine receptivity. Ann N Y Acad Sci 2001, 943:49-54.

95. Garcia-Velasco JA, Coelingh Bennink HJ, Epifanio R, Escudero E, Pellicer A, Simon C: High-dose recombinant LH add-back strategy using high-dose $\mathrm{GnRH}$ antagonist is an innovative protocol compared with standard GnRH antagonist. Reprod Biomed Online 2007, 15:280-287.

96. Bosch E, Labarta E, Crespo J, Simon C, Remohi J, Pellicer A: Impact of luteinizing hormone administration on gonadotropin-releasing hormone antagonist cycles: an age-adjusted analysis. Fertil Steril 2011, 95:1031-1036.

97. Rombauts L, Healy D, Norman RJ: A comparative randomized trial to assess the impact of oral contraceptive pretreatment on follicular growth and hormone profiles in $\mathrm{GnRH}$ antagonist-treated patients. Hum Reprod 2006, 21:95-103.

98. Pinkas H, Sapir O, Avrech OM, Ben Haroush A, Ashkenzi J, Fisch B, Farhi J: The effect of oral contraceptive pill for cycle scheduling prior to $\mathrm{GnRH}$ antagonist protocol on IVF cycle parameters and pregnancy outcome. J Assist Reprod Genet 2008, 25:29-33.

99. Bendikson K, Milki AA, Speck-Zulak A, Westphal LM: Comparison of GnRH antagonist cycles with and without oral contraceptive pretreatment in potential poor prognosis patients. Clin Exp Obstet Gynecol 2006, 33:145-147.

100. Griesinger G, Venetis CA, Marx T, Diedrich K, Tarlatzis BC, Kolibianakis EM: Oral contraceptive pill pretreatment in ovarian stimulation with $\mathrm{GnRH}$ antagonists for IVF: a systematic review and meta-analysis. Fertil Steril 2008, 90:1055-1063.

101. Griesinger G, Kolibianakis EM, Venetis C, Diedrich K, Tarlatzis B: Oral contraceptive pretreatment significantly reduces ongoing pregnancy likelihood in gonadotropin-releasing hormone antagonist cycles: an updated meta-analysis. Fertil Steril 2010, 94:2382-2384.

102. Guivarc'h-Levêque A, Homer L, Arvis P, Broux PL, Moy L, Priou G, Vialard J, Colleu D, Dewailly D: Programming in vitro fertilization retrievals during working days after a gonadotropin-releasing hormone antagonist protocol with estrogen pretreatment: does the length of exposure to estradiol impact on controlled ovarian hyperstimulation outcomes? Fertil Steril 2011, 96:872-876

103. Cedrin-Durnerin I, Guivarc'h-Leveque A, Hugues JN: Pretreatment with estrogen does not affect IVF-ICSI cycle outcome compared with no pretreatment in $\mathrm{GnRH}$ antagonist protocol: a prospective randomized trial. Fertil Steril 2012, 97:1359-1364

104. Smulders B, van Oirschot SM, Farquhar C, Rombauts L, Kremer JA: Oral contraceptive pill, progestogen or estrogen pre-treatment for ovarian stimulation protocols for women undergoing assisted reproductive techniques. Cochrane Database Syst Rev 2010, 1:CD006109.

105. Gustofson RL, Segars JH, Larsen FW: Ganirelix acetate causes a rapid reduction in estradiol levels without adversely affecting oocyte maturation in women pretreated with leuprolide acetate who are at risk of ovarian hyperstimulation syndrome. Hum Reprod 2006, 21:2830-2837.

106. Lainas TG, Sfontouris IA, Zorzovilis IZ, Petsas GK, Lainas GT, Alexopoulou E, Kolibianakis EM: Flexible GnRH antagonist protocol versus $\mathrm{GnRH}$ agonist long protocol in patients with polycystic ovary syndrome treated for IVF: a prospective randomised controlled trial (RCT). Hum Reprod 2010, 25:683-689.

107. Al-Inany HG, Abou-Setta AM, Aboulghar M: Gonadotrophin-releasing hormone antagonists for assisted conception. Cochrane Database Syst Rev 2006, 3:CD001750.

108. Xiao J, Chen S, Zhang C, Chang S: Effectiveness of GnRH antagonist in the treatment of patients with polycystic ovary syndrome undergoing IVF: a systematic review and meta analysis. Gynecol Endocrinol 2012, 29:187-191.

109. Lainas TG, Sfontouris IA, Zorzovilis IZ, Petsas GK, Lainas GT, Kolibianakis EM: Management of severe early ovarian hyperstimulation syndrome by re-initiation of GnRH antagonist. Reprod Biomed Online 2007, 15:408-412.

110. Bonduelle M, Oberye J, Mannaerts B, Devroey P: Large prospective, pregnancy and infant follow-up trial assures the health of 1000 fetuses conceived after treatment with the $\mathrm{GnRH}$ antagonist ganirelix during controlled ovarian stimulation. Hum Reprod 2010, 25:1433-1440. 
111. Boerrigter PJ, De Bie JJ, Mannaerts BM, van Leeuwen BP, Passier-

Timmermans DP: Obstetrical and neonatal outcome after controlled ovarian stimulation for IVF using the GnRH antagonist ganirelix. Hum Reprod 2002, 17:2027-2034.

112. Ganirelix: prescribing information. Whitehouse Station, NJ: Merck Sharp \& Dohme Corp; 2008. Available at: http://www.merck.com/product/usa/ pi_circulars/g/ganirelix/ganirelix_pi.pdf.

113. Nilsson L, Andersen AN, Lindenberg S, Hausken J, Andersen CY, Kahn JA: Ganirelix for luteolysis in poor responder patients undergoing IVF treatment: a Scandinavian multicenter 'extended pilot study'. Acta Obstet Gynecol Scand 2010, 89:828-831.

114. Stadtmauer LA, Sarhan A, Duran EH, Beydoun H, Bocca S, Pultz B, Oehninger $\mathrm{S}$ : The impact of a gonadotropin-releasing hormone antagonist on gonadotropin ovulation induction cycles in women with polycystic ovary syndrome: a prospective randomized study. Fertil Steril 2011, 95:216-220.

doi:10.1186/1477-7827-11-20

Cite this article as: Copperman and Benadiva: Optimal usage of the $\mathrm{GnRH}$ antagonists: a review of the literature. Reproductive Biology and Endocrinology 2013 11:20.

\section{Submit your next manuscript to BioMed Central and take full advantage of:}

- Convenient online submission

- Thorough peer review

- No space constraints or color figure charges

- Immediate publication on acceptance

- Inclusion in PubMed, CAS, Scopus and Google Scholar

- Research which is freely available for redistribution 